\title{
A UESB como apoio ao enfrentamento da pandemia Covid-19: o caso da produção de antisséptico - Campus Itapetinga-BA
}

\section{The UESB as support to face the Covid-19 pandemic: the case of antiseptic production - Campus Itapetinga-BA}

\author{
Andréa Gomes da Silva ${ }^{1}$ \\ Henrique Luis da Silva Santos ${ }^{2}$ \\ Alex Aguiar Figueiredo ${ }^{3}$ \\ Fabiany Cruz Gonzaga ${ }^{4}$ \\ Cristiane Patrícia de Oliveira ${ }^{5}$
}

Resumo: Neste artigo, abordamos o processo de produção de álcool antisséptico $70 \%$ líquido pela Universidade Estadual do Sudoeste da Bahia (UESB), Campus Itapetinga, como forma de contribuir para o enfrentamento da Covid-19. Trata-se de um relato de experiência quanto à produção e distribuição de sanitizantes. Tais procedimentos seguiram as etapas de estudos dos protocolos da OMS e da ANVISA para produção do álcool 70\% em situação de combate à pandemia, e foram adaptados e desenvolvidos pelo Laboratório de Tecnologia de Produtos de Origem Vegetal (LTPOV). A estrutura da UESB e a expertise da equipe para a produção do álcool mostraram a capacidade desse ambiente universitário para se adaptar e cumprir com sua responsabilidade social em torno do enfrentamento de diferentes situações, nesse caso, a pandemia Covid-19.

Palavras-chave: Álcool 70\%. Coronavírus. Higienização das mãos. Vírus.

\begin{abstract}
In this article, we discuss the production process of antiseptic alcohol 70\% liquid by the State University of Southwest Bahia (UESB), Campus Itapetinga, as a way to contribute to the confrontation of Covid-19. This is an experience report regarding the production and distribution of sanitizers. Such procedures followed the stages of studies of the protocols of WHO and ANVISA for the production of

\footnotetext{
${ }^{1}$ Universidade Estadual do Sudoeste da Bahia (UESB), Doctor Scientiae. Professora Titular. Laboratório de Tecnologia e Produtos de Origem Vegetal (LTPOV). E-mail: agomes@uesb.edu.br.

2 Pesquisador. Doutor em Ciências da Engenharia Ambiental pela Universidade de São Paulo (USP). Colaborador do Projeto de extensão: Produção de antissépticos para o combate a Covid-19. E-mail: henriagro@gmail.com.

3 Zootecnista. Técnico Universitário. Laboratório de Nutrição Animal, Universidade Estadual do Sudoeste da Bahia (UESB).E-mail: alexaf_zootecnista@hotmail.com.

${ }^{4}$ Universidade Estadual do Sudoeste da Bahia (UESB), Doctor Scientiae, Professora Adjunta. Núcleo de Pesquisa, Empreendedorismo e Inovação em Química. Departamento de Ciências Naturais (DCEN). E-mail: fabianycruz@uesb.edu.br.

${ }^{5}$ Universidade Estadual do Sudoeste da Bahia (UESB). Professora Titular. Laboratório de Análise de Alimentos. Email: E-mail: cristianepatricia@hotmail.com.
} 
$70 \%$ alcohol in a situation of combat to the pandemic, and were adapted and developed by the Laboratory of Technology of Products of Vegetable Origin (LTPOV). The structure of UESB and the expertise of the team for the production of alcohol showed the capacity of this university environment to adapt and comply with its social responsibility around coping with different situations, in this case the pandemic Covid-19.

Keywords: Alcohol 70\%. Coronavirus. Sanitizer hand. Virus.

\section{Introdução}

No final de janeiro de 2020, a Organização Mundial da Saúde (OMS) caracterizou a doença causada pelo vírus Sars-CoV-2 (Covid-19) como situação de emergência em saúde pública de interesse internacional. Posteriormente, em março do referido ano, decretou situação de pandemia devido ao agravamento da situação (WHO, 2020). A Covid-19 foi detectada originalmente na cidade de Wuhan, na província de Hubei, na China, em dezembro de 2019. A doença apresenta um espectro clínico variável, que inclui de quadros assintomáticos a graves, e a transmissão ocorre de pessoa a pessoa, por meio de gotículas de saliva ou secreção nasal. Até o momento, não existem vacinas ou tratamentos específicos para combatê-la (WHO, 2020; Brasil, 2020). No Brasil, a detecção dessa nova doença respiratória é acompanhada de incertezas, tanto em relação às suas características epidemiológicas, à propagação e virulência do patógeno envolvido (vírus Sars-CoV-2), quanto às medidas de isolamento e, particularmente, ao denominado "novo normal".

A Constituição Federal Brasileira, no artigo 207, estabelece que a universidade constitui um ente social dotado do princípio da indissociabilidade entre ensino, pesquisa e extensão. Moita e Andrade (2009) dispõem que, caso não se observe essa tridimensionalidade, "ou se enfatiza a produção do novo saber, ou a intervenção nos processos sociais, ou ainda a transmissão de conhecimentos na formação profissional". Dessa forma, as instituições de ensino, detentoras de todo um universo de conhecimento, podem contribuir decisivamente com atividades de pesquisa e extensão em situações emergenciais, como é o caso da pandemia do novo coronavírus, por exemplo.

A ausência de vacina contra o novo coronavírus reforça a necessidade de a população e os profissionais da saúde adotarem medidas de prevenção contra a contaminação, bem como a transmissão do vírus. Diante desse contexto, criar um hábito de higiene tornou-se essencial no dia a dia da população, assim como a necessidade de aplicação de medidas de prevenção contra a covid-19, como o uso de óculos de proteção ou protetor facial, luva, máscara e higienização das mãos. Aliado a isso, a pandemia traz um desafio extra para a saúde, a necessidade de utilização de antisséptico e a demanda pelo insumo nos diversos segmentos da sociedade.

Nesse contexto, a produção de antissépticos destaca-se como uma forma de contribuição da universidade para o enfrentamento do Sars-CoV-2. Os autores apresentam um relato da experiência do projeto de extensão "Produção de antissépticos para o combate à Covid-19". Submetido e aprovado pelo 
Edital 10/2020, esse Projeto prevê a motivação, o planejamento, a execução e distribuição de solução líquida de álcool antisséptico 70 \% glicerinado.

\section{Abordagem metodológica}

O relato baseia-se na experiência relacionada ao projeto de extensão "Produção de antissépticos para o combate à Covid-19", no que tange ao planejamento, aquisição de matérias-primas e embalagens, adequação do Laboratório de Tecnologia de Produtos de Origem Vegetal (LTPOV), formulação segundo legislação e protocolos oficiais, processo de produção, desenvolvimento de rotulagem obrigatória, controle de qualidade, protocolos de garantia da qualidade, planejamento de distribuição, segundo o público-alvo, de acordo com o avanço ou retrocesso da taxa de disseminação, bem como sua rastreabilidade.

Quanto à questão temporal, a experiência ocorreu entre o mês de abril e a primeira semana de julho de 2020. Os dados aqui relatados traduzem a vivência presencial, que surgiu da motivação e concretizou-se em ações, observações, aquisição de matérias primas, parcerias com instituições e sociedade civil, estudos e discussões entre os profissionais envolvidos na produção.

\section{Estruturação do Laboratório de Tecnologia de produtos de Origem vegetal}

O Laboratório de Tecnologia de Produtos de Origem Vegetal (LTPOV) tem a finalidade de ensino de graduação e pós-graduação do curso de engenharia de alimentos e áreas afins. O referido Laboratório dispõe de equipamentos de análise e de uma unidade de processamento de alimentos, conforme Figura 1. Foi estabelecido um diagrama de processo da produção usando a metodologia Business Process Model and Notation (BPMN), que permite entender o controle dos processos.

Figura 1 - Leiaute e fluxo do processo de produção de álcool etílico no LTPOV.

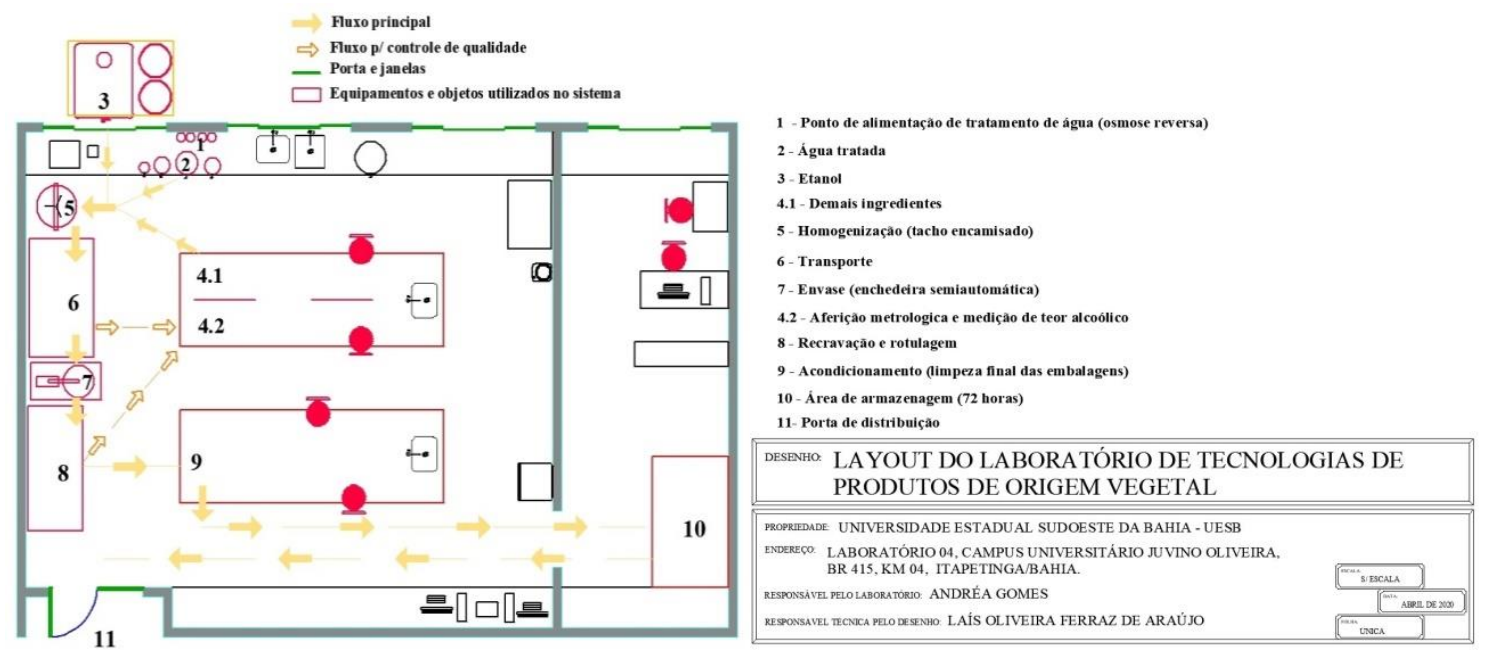

Fonte: Dados do projeto de extensão "Produção de antissépticos para o combate à Covid-19”.

Foram feitas adaptações quanto à instalação de um sistema de tratamento da água por Osmose Reversa, cedida pelo laboratório de química. Esse sistema possibilita a purificação da água em relação a 
contaminantes físicos e microbiológicos e também quanto à determinação do fluxo racional de processo, levando-se em consideração aspectos como segurança, controle, higiene, fluxos racionais e ergonômicos. A capacidade de processamento instalada é de $1000 \mathrm{~L}^{-1}$ de álcool etílico a $70 \%$ (INPM), glicerinado para higienização das mãos, operando em bateladas, em 8 horas de trabalho. $O$ processamento segue Procedimentos Operacionais Padronizados (POH), Procedimentos Padronizados de Higiene Operacional (PPHO). A formulação do antisséptico e o treinamento da mão de obra foram desenvolvidos e revisados pela Prime Engenharia e Consultoria e equipe docente envolvida.

\section{Estabelecimento de parcerias para aquisição do álcool etílico}

Foram tentados diversos meios para viabilizar a aquisição de álcool para a realização do projeto. Entre esses, optou-se pela solicitação de doação e contato com a usina Agro Indústrias do Vale do São Francisco S/A (AGROVALE), localizada na cidade de Juazeiro, Bahia, distante $800 \mathrm{~km}$ de Itapetinga. A AGROVALE foi, portanto, a primeira empresa a ser contatada para apresentação do projeto e solicitação de parceria. No início de junho, o Conselho Regional de Química (CRQ-7. a região) contatou a Responsável Técnica (RT) para intermediar a doação de etanol a $96^{\circ} \mathrm{GL}$, realizada pela Usina Santa Maria, localizada em Medeiros Neto, a $400 \mathrm{~km}$ de distância de Itapetinga. Cada empresa doou um volume de 1.000 litros de álcool.

A AGROVALE cedeu um container apropriado para transportar o álcool, fator determinante para o processo logístico da aquisição, segurança no transporte e armazenamento dessa matéria prima. A UESB ficou responsável pela infraestrutura logística e custo de transporte, disponibilizando-a para o translado do material. Também contou com a participação de motoristas experientes em transporte de carga inflamável. Ao longo dos meses de maio, junho e primeira semana de julho, foram produzidos cerca de 2.300 litros de álcool antisséptico para as mãos e superfícies.

A Associação dos Produtores de Cachaça e Derivados de Itapetinga (APC-ITA), por meio do Centro de Estudos e Ação Social (CEAS), contatou as professoras e a administração, na busca de parceira para produção de álcool antisséptico, mediante a produção da cachaça de alambique orgânica. O resíduo chamado de "cabeça da cachaça" foi usado para obter álcool etílico com teor de 75 a 79 \% (INPM), padrão mínimo das formulações, segundo os protocolos de produção do LTPOV. Por meio da PróReitoria de Extensão, foi estabelecido um termo de cooperação entre a UESB e o CEAS. O álcool produzido com a fabricação da cachaça foi batizado de "álcool floral da cachaça", devido aos aromas incorporados no processo de fabricação dessa bebida. A APC-ITA e o CEAS são os responsáveis por distribuir o álcool floral, em embalagem de $500 \mathrm{~mL}$ para a cidade de Itarantim, Bahia, e outras em Minas Gerais, também aos movimentos sociais e periferias de Salvador (RODRIGUES, 2020).

O HUB-Itapetinga SOS Covid-19, articulador e responsável pela captação financeira e material, de doadores no Brasil e exterior (Suiça), foi outro parceiro importante na produção e distribuição do álcool antisséptico. Trata-se, portanto, de um grupo formado por professores, técnicos e estudantes da UESB e Instituto Federal Baiano (IFBaiano), Campus de Itapetinga, empresas privadas, sindicatos, 
profissionais liberais e sociedade civil, com o objetivo de organizar ações e agregar pessoas interessadas em oferecer serviços solidários à população para enfrentar a crise do Covid-19 (AMORIM, 2020).

Na parceria HUB e APC-ITA, os objetivos eram comuns: distribuir o álcool gratuitamente para a classe trabalhadora, população em vulnerabilidade, profissionais da linha de frente no combate à pandemia, como os servidores públicos da saúde, educação e segurança, por exemplo. Ressalta-se, nesse contexto, que as parcerias firmadas com empresas e associações surgem como uma alternativa importante para que as empresas se engajem nas ações com posturas e comportamentos que visem o benefício da coletividade e o compromisso com pessoas e valores humanos.

Vale ressaltar que as ações de idealização, planejamento e produção ocorreram em um prazo menor que vinte dias, de forma que, no dia 14 de abril de 2020, a planta do LTPOV já estava em operação.

\section{A produção de álcool 70\% e os protocolos}

A Agência Nacional de Vigilância Sanitária (ANVISA) estabeleceu normas técnicas de adequação para que empresas, universidades, institutos federais, não regularizados por esse órgão como fabricantes de álcool 70\%, pudessem fornecer o produto em caráter extraordinário, em prol de pacientes, profissionais da saúde e população em geral. No cenário de crise relatado, fez-se uma adequação estrutural para a produção de álcool 70\% (INPM) glicerinado, na forma de solução.

A OMS define como antissépticas substâncias que desinfetam, inibindo parcial ou totalmente, o desenvolvimento de microrganismos sobre tecidos vivos sem causar danos (OMS, 2009).

Desde 2010, por meio da Resolução de Diretoria Colegiada (RDC) n. ${ }^{\circ}$ 42/2010 (BRASIL, 2010), a ANVISA dispõe sobre a obrigatoriedade de os serviços de saúde do país, no atendimento a pacientes, disponibilizarem preparação alcoólica para fricção antisséptica das mãos, com o objetivo de controlar as infecções relacionadas à assistência à saúde. No contexto atual, o álcool antisséptico tornou-se um aliado no controle da disseminação do vírus Sars-CoV-2, quando não é possível lavar as mãos com água e sabão ou sabonete.

O processo inicial da produção de antissépticos procedeu-se com pesquisa e estudo da legislação que regula a produção e requisitos para execução desses produtos. A vigência da pandemia de Covid-19 requisitou uma elevada demanda dessas substâncias em um curto período, de modo que a ANVISA emitiu notas técnicas (NT) e resoluções, entre as quais se destacam: a RDC n. ${ }^{\circ}$ 350/2020 e a NT n. ${ }^{\circ}$ 3/2020 (BRASIL, 2020b; BRASIL, 2020a).

A RDC n. $350 / 2020$, publicada em 20 de março de 2020, "define os critérios e os procedimentos extraordinários e temporários para a fabricação e comercialização de preparações antissépticas ou sanitizantes oficiais sem prévia autorização da ANVISA e dá outras providências, em virtude da emergência de saúde pública internacional, relacionada ao Sars-CoV-2”. No art. 3º a referida Resolução dispõe: "Fica permitida de forma temporária e emergencial, sem prévia autorização da Anvisa, a fabricação e comercialização das preparações antissépticas ou sanitizantes oficinais [...]” (BRASIL, 2020b). 
Entre as suas publicações, a OMS possui um "Guia para produção de gel antisséptico", com versão traduzida pela Universidade do Estado de São Paulo. Esses documentos referenciam à formulação do álcool 70\% glicerinado com testes e orientações quanto à matéria-prima e produto final.

A Nota Técnica (NT) n. 3/2020, publicada em 24 de março de 2020, trata de orientações gerais para a doação de álcool $70 \%$, entre as quais destaca os requisitos cumpridos pela equipe: (i) $\mathrm{O}$ estabelecimento deve dispor de responsável técnico habilitado segundo órgão de classe; (ii) A Vigilância Sanitária Estadual ou Municipal deve ser comunicada da fabricação do produto a ser doado (BRASIL, 2020a).

\section{Rotulagem obrigatória}

Embora indicados para o auxílio na manutenção da saúde, os antissépticos possuem riscos inerentes à manipulação de substâncias químicas. No caso do álcool antisséptico 70\%, há riscos de irritação dérmica e das mucosas aéreas, e também de incêndio, devido à significativa inflamabilidade da matéria-prima, o álcool etílico. Em relação a esse item, as informações de rótulo são essenciais para o manuseio seguro do produto.

As orientações para rótulos estão descritas na NT n. ${ }^{\circ}$ 03/2020 (BRASIL, 2020a). Além das informações obrigatórias, optou-se em destacar a mensagem que proíbe a comercialização do produto, reafirmando sua utilidade e indicação. Um aspecto também importante foi o destaque para os parceiros que doaram a matéria-prima e para o grupo HUB SOS Covid-19 (Figura 2).

A outra preocupação da equipe foi garantir a qualidade e rastreabilidade do produto. Para tanto, estabeleceram-se números de lotes e de controle de distribuição/doação com a utilização de fichas próprias, assinadas pela Instituição/pessoa atendida. Ademais, disponibilizou-se um canal de comunicação para o consumidor solicitar informações, fazer elogios, reclamações e/ou dar sugestões (Figura 2).

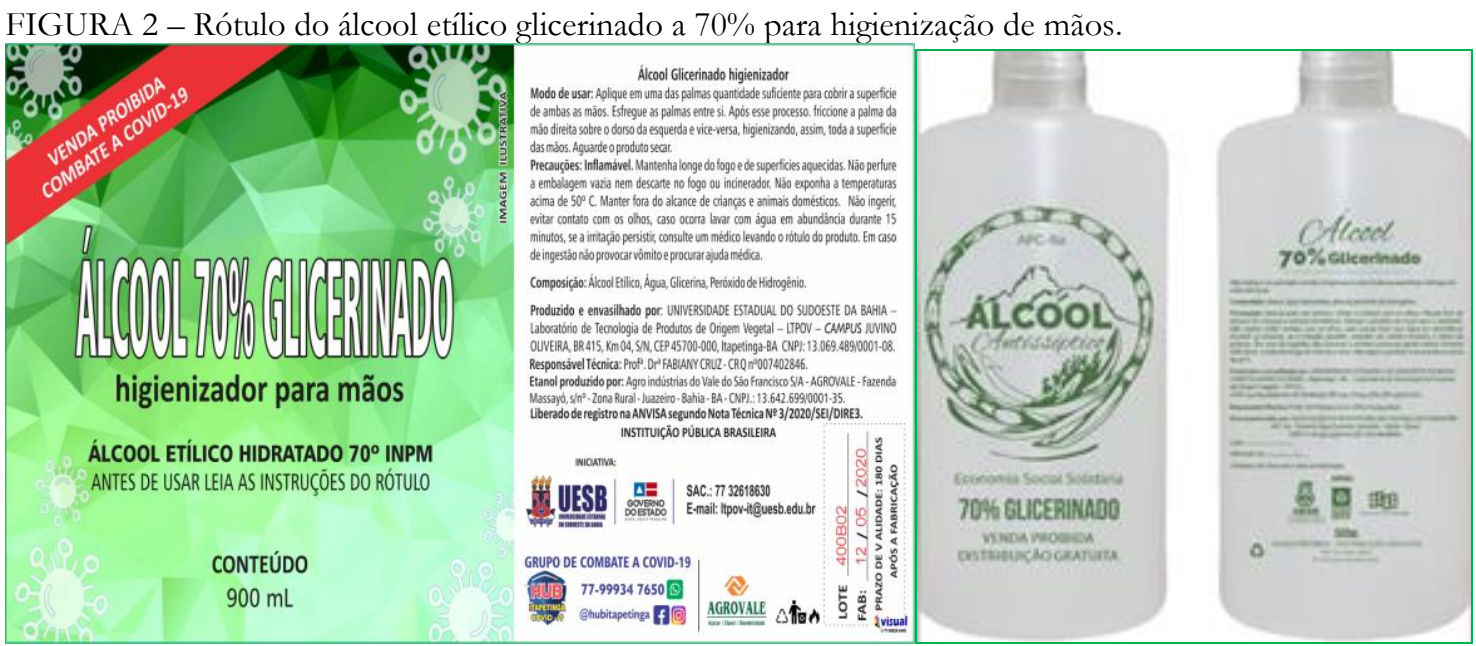

Fonte: Dados do projeto de extensão "Produção de antissépticos para o combate à Covid-19". 


\section{Estratégias para distribuição do álcool 70\% glicerinado}

Em cumprimento aos critérios da Nota Técnica n. ${ }^{\circ}$ 03/2020 (BRASIL, 2020a), o álcool produzido destinou-se a associações de profissionais de saúde, bem como a outros locais classificados de essenciais. Foram atendidos os seguintes órgãos/setores: doze unidades de saúde (PSF e atenção básica), Hospital Cristo Redentor (HCR), Unidade de Pronto Atendimento (UPA), unidades de segurança pública (Polícias civil e militar, guarda municipal, Comutran), Posto da Polícia Rodoviária, Cemitério Municipal, Barreiras Sanitárias, Lar Laura de Carvalho, Associação dos Agentes Comunitários, conforme mostra a Figura 3. A depender da dinâmica da pandemia, o raio de ação das entregas, bem como o público, poderá ser estendido levando-se em consideração a segurança dos consumidores.

Os três campi da UESB, situados na região Sudoeste do estado da Bahia, também foram beneficiados com o álcool produzido e destinado para uso dos trabalhadores e trabalhadoras. Além dos benefícios à saúde, tal iniciativa gerou uma economia significativa para a Instituição.

O HCR e a UPA são responsáveis pela regulação de pacientes com o novo coronavírus para as cidades de Salvador ou Vitória da Conquista. Embora não tenham sido cadastradas como referência para o tratamento de Covid-19, essas unidades foram contempladas com a doação porque se toda a região tiver taxa de internação semelhante, os moradores da cidade correm mais risco com a falta de leitos.

Uma parte do álcool produzido em parceria com o APC-ITA (10\%) destinou-se à UESB para uso interno. A Associação e o CEAS ficaram responsáveis pela distribuição do restante, realizada na região de abrangência da Associação, norte do estado de Minas Gerais, Salvador e região metropolitana.

Em um momento de escassez de saneantes, o projeto beneficiou o município no combate à pandemia por localizar suas ações de forma estratégica para impedir a disseminação do vírus e proteger as pessoas, sobretudo aquelas em situação de maior vulnerabilidade. Foram beneficiárias diretas as várias unidades de saúde, segurança pública e privada, educação, associações e outros serviços essenciais. 
FIGURA 3 - Localização geográfica da distribuição do álcool 70\% (INPM) glicerinado.

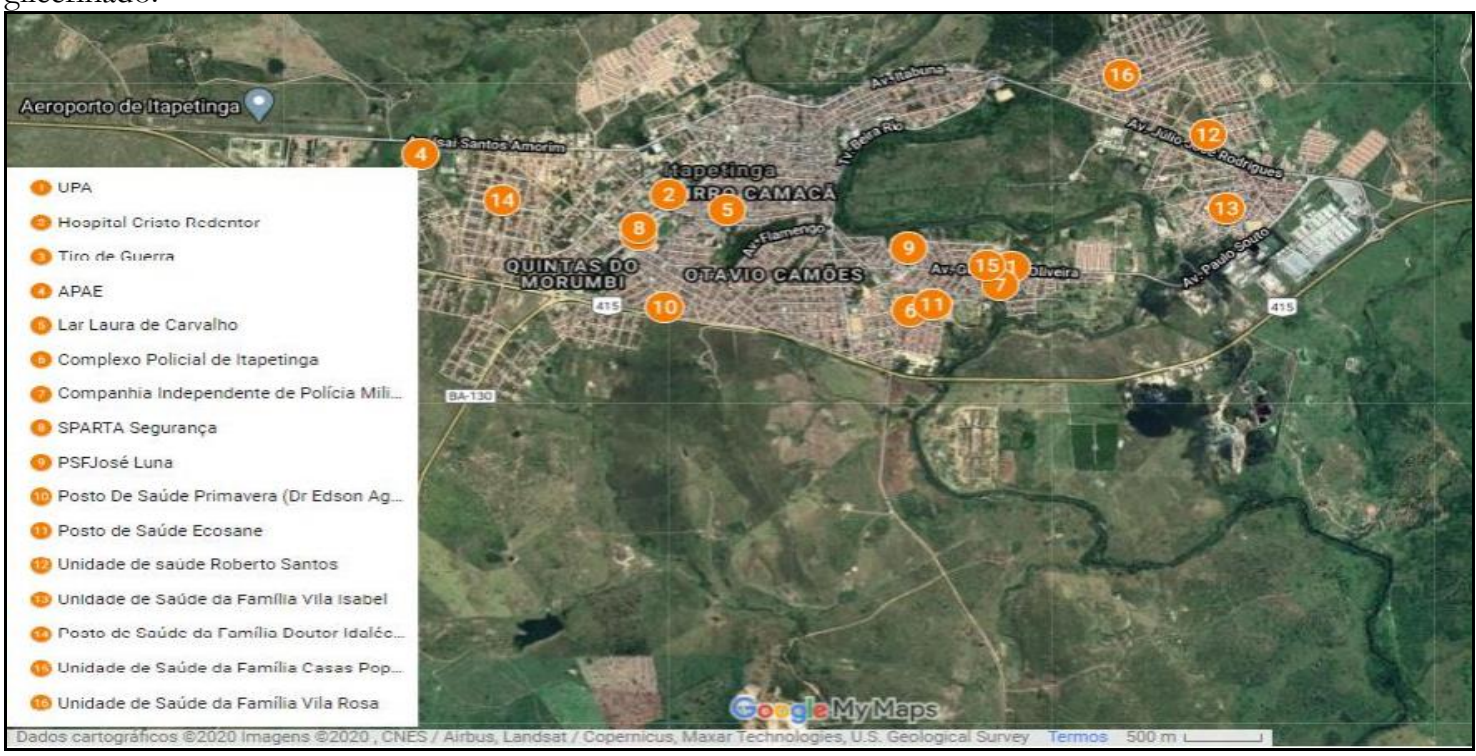

Fonte: Dados do projeto de extensão "Produção de antissépticos para o combate à Covid-19”.

\section{Considerações finais}

Por ser um momento de calamidade pública, espera-se, em caráter provisório, que na condição de educadora, a UESB - Campus Itapetinga - faça parte de um conjunto de ações de atenção à saúde, solidariedade e responsabilidade social, em parceria com o HUB-Itapetinga SOS Covid-19.

Em um momento de escassez de saneantes, o projeto beneficiou o município no combate à pandemia por localizar suas ações de forma estratégica para impedir a disseminação do vírus e proteger as pessoas, sobretudo aquelas em situação de maior vulnerabilidade. Foram beneficiárias diretas as várias unidades de saúde, segurança pública e privada, educação, associações, bem como outros serviços essenciais.

Não obstante todas as dificuldades que nos são impostas, os servidores da UESB se adaptaram e se mobilizaram, em um curto espaço de tempo, em prol do compromisso com uma educação emancipadora e socialmente referenciada, para enfrentar a pandemia do coronavírus. Fica evidente, portanto, a importância da indissociabilidade entre ensino, pesquisa e extensão na construção do projeto para a educação pública, de qualidade, laica, socialmente referenciada, financiada com recursos públicos e de caráter emancipatório.

\section{Referências}

Agência Nacional de Saúde Suplementar - ANS. Beneficiários de planos privados de saúde, por cobertura assistencial (Brasil 2010-2020). Rio de Janeiro: Agência Nacional de Saúde Suplementar; 2020 [acesso 21 abril 2020]. Disponível em: https://www.ans.gov.br/perfil-do-setor/dados-gerais

BBC News Brasil [Internet]. São Paulo: Vinícius Lemos; 2020 [citado em 25 jun 2020]. Ministério Público do Trabalho analisa morte de doméstica no RJ após patroa ter coronavírus; [aproximadamente 2 telas]. Disponível em: Disponível em: https://www.bbc.com/portuguese/brasil-51982465 
Brasil. Agência Nacional de Vigilância Sanitária. Nota Técnica número 03/2020. Brasília: Anvisa; 2020. 4p. Disponível: http://portal.anvisa.gov.br/documents/2857848/5680794/NT+FINAL.pdf/361b79b39277-452a-835a-3b9ef9be1bb9. Acessado em 28 mar.2020(a)

Brasil. Agência Nacional de Vigilância Sanitária. Resolução de Diretoria Colegiada (RDC) 42/2010. Brasília: Anvisa; 2010. 3p. Disponível:

https://bvsms.saude.gov.br/bvs/saudelegis/anvisa/2010/res0042 25 10_2010.html.Acessado em 28 $\underline{\operatorname{mar} .2020}$

Brasil. Agência Nacional de Vigilância Sanitária. Resolução de Diretoria Colegiada (RDC) 350/2020. Brasília: Anvisa; 2010. 3p. Disponível:

http://portal.anvisa.gov.br/documents/10181/5809525/RDC 350_2020_.pdf/2929b492-81cd-40898ab5-7f3aabd5df61. Acessado em 28 mar.2020(b)

Brasil. Decreto n. ${ }^{\circ}$ 7.602, de 7 de novembro de 2011: dispõe sobre a Política Nacional de Segurança e Saúde no Trabalho - PNSST. Diário Oficial da União [Internet]. 8 nov 2011 [citado em 5 abr 2020]. Disponível em: Disponível em: http://www.planalto.gov.br/ccivil 03/_ato2011$\underline{014 / 2011 / \text { decreto/d7602.htm }}$

Brasil. Ministério da Saúde. Portaria n. ${ }^{\circ}$ 1.823, de 23 de agosto de 2012: institui a Política Nacional de Saúde do Trabalhador e da Trabalhadora. Diário Oficial da União [Internet]. 2012 [citado em 5 abr 2020]. Disponível em: Disponível em: https://bvsms.saude.gov.br/bvs/saudelegis/gm/2012/prt1823 2308 2012.html.

Brasil. Ministério da saúde. Secretaria da Gestão do Trabalho e da Educação na Saúde. Protocolo n. ${ }^{\circ}$ 008/2011: protocolo da Mesa Nacional de Negociação Permanente do Sistema Único de Saúde - MNNP SUS. Brasília, DF; 2011 [citado em 5 abr 2020]. Disponível em: Disponível em: https://portalarquivos2.saude.gov.br/images/pdf/2014/marco/10/protocolo08.pdf

Brasil. Ministério da Saúde. Secretaria de Atenção Especializada à Saúde. Departamento de Atenção Hospitalar, Domiciliar e de Urgência. Coordenação-Geral de Urgência. Força Nacional do Sistema Único de Saúde. Protocolo de manejo clínico para o novo coronavírus (2019-nCoV) [nternet]. Brasília (DF); 2020 [citado em 23 jun 2020]. Disponível em: Disponível em: http://189.28.128.100/dab/docs/portaldab/documentos/20200330 ProtocoloManejo ver06 Final. pdf

Gallasch CH, Cunha ML, Pereira LAS, Junior JSS. Prevention related to the occupational exposure of health professionals workers in the Covid-19 scenario. Rev. enferm. UERJ. [nternet]. 2020[cited 2020 jun 20]; 28:e49596. Available from:

https://www.epublicacoes.uerj.br/index.php/enfermagemuerj/article/view/49596/33146

Koh D. Occupational risks for Covid-19 infection. Occup Med. 2020 [citado em 24 jun 2020];70(1):3-5. Disponível em: Disponível em : https://doi.org/10.1093/occmed/kqaa036

Li Q, Guan X, Wu P, Wang X, Zhou L, Tong Y, et al. Early transmission dynamics in Wuhan, China, of novel coronavirus-infected pneumonia. N Engl J Med. 2020 [citado em 24 jun 2020];382:1199-207. Disponível em: Disponível em : https://doi.org/10.1056/NEJMoa2001316

MOITA, Filomena Maria Gonçalves da Silva Cordeiro and ANDRADE, Fernando Cézar Bezerra de. Ensino-pesquisa-extensão: um exercício de indissociabilidade na pós-graduação. Rev. Bras. Educ. [online]. 2009, vol.14, n.41, pp.269-280.

Organização mundial de Saúde, OMS. WHO Guidelines on Hand Hygiene in Health Care.2009. Disponível em: 
https://apps.who.int/iris/bitstream/handle/10665/44102/9789241597906 eng.pdf;jsessionid=E22A91E A3EAE319D54FFF566EBD2CA7E?sequence=1. Acessado em : 30 mar. 2020.

World Economic Forum [Internet]. Genebra; 2020 [citado em 5 abr 2020]. The job description for a Covid-19 community health worker - and how this could fight US unemployment; [aproximadamente 2 telas]. Disponível em: Disponível em: https://www.weforum.org/agenda/2020/03/retrainingunemployed-fight-covid-19/

World Health Organization (WHO). Guide to Local Production: WHO-recommended Handrub

Formulations. Revisado em abril de 2010.9p. Disponível em: https://www.who.int/gpsc/5may/Guide_to_Local_Production.pdf. Traduzido por: Marwin Bravin Gabriel Leszczinski Marina Araújo Vieira Filipe Canto Oliveira

World Health Organization. WHO Director-General's opening remarks at the media briefing on Covid19-11 March 2020. 2020 [cited 2020 mai 23]. Available from:

https://www.who.int/dg/speeches/detail/who-director-general-s-opening-remarks-at-the-media-briefingon-covid-19---11-march-2020.

World Health Organization. WHO Director-General's statement on IHR Emergency Committee on Novel Coronavirus (2019-nCoV). Geneva: WHO; 2020. 2020 [cited 2020 apr 16]. Available from: https://www.who.int/news-room/detail/23-01-2020-statement-on-the-meeting-of-the-internationalhealth-regulations-(2005)-emergency-committee-regarding-the-outbreak-of-novel-coronavirus-(2019ncov).

RODRIGUES, JOABES. Combate ao Covid-19 álcool floral da cachaça produzida em Itarantim será distribuído essa semana. Acesso em 01/07/2020. Disponível em:

http://www.cronicasdeitarantim.com.br/v1/2020/05/17/itarantim-alcool-glicerinado-da-cachacaproduzida-em-itarantim-sera-distribuido-essa-semana/.

AMORIM, VALCELENE. A UESB potencializa a produção do álcool no interior da Bahia. Revista eletrônica da UESB. v. 5, n. 2, 2020. Acesso em 1/07/2020. Disponível em:

http://www2.uesb.br/revistaeletronica/contra-o-coronavirus-universidades-potencializam-a-producaode-alcool-no-interior-da-bahia/.

Agradecimentos: Às usinas AGROVALE e Santa Maria, pela doação do álcool etílico. À ADUSB, pela doação de recursos da campanha a solidariedade resiste ao HUB. Aos membros que integram a equipe de produção de antissépticos: Profa. Dra. Simone Andrade Gualberto; Prof. Dr. Dimas Oliveira; $M S$ c. George (zootecnista, téc. universitário); Vagner Ferraz (Coordenador do módulo de laboratórios); aos discentes Janine Lima Soares (eng. de alimentos) e Ueslei Souza Santos (pedagogia). Aos profissionais de engenharia, egressos da UESB, pela assessoria na supervisão de documentos: $M S$ c. Laís O. Ferraz de Araújo e Juarez da Silva Souza Júnior (Prime Engenharia e Consultoria). 